\title{
PENGEMBANGAN BAHAN AJAR KONSEP DASAR IPS BERBASIS KARAKTER UNTUK MAHASISWA PGSD
}

\author{
Monalisa Gherardini ${ }^{1}$, Aren Frima ${ }^{2}$ \\ STKIP-PGRI Lubuklinggau ${ }^{1,2}$ \\ gherardinimona@gmail.com
}

\begin{abstract}
ABSTRAK
Artikel ini membahas tentang proses dalam merancang bahan ajar berupa Buku ajar Konsep Dasar IPS pada Mahasiswa PGSD STKIP PGRI Lubuklinggau. Metode yang digunakan penulis dalam merancang bahan ajar merupakan bagian atau dua tahapan awal dari model pengembangan ADDIE yang terdiri dari tahap analisis, desain, deleopment, implementasi, dan evaluasi. Tahap analisis bertujuan untuk mengidentifikasi kurikulum, kebutuhan akan bahan ajar, sedangkan tahap desain untuk merancang kerangka Buku Ajar dan instrumen penelitian. Berdasarkan kedua tahap tersebut diperoleh konsep pendidikan Karakter yang bisa diintegrasikan ke dalam pembelajaran dengan cara menyajikan dalam Buku Konsep Dasar IPS agar pembelajaran Konsep Dasar IPS lebih bermakna dan dapat menjadi salah satu bahan bacaan berkarakter bagi mahasiswa. Hasil analisis diperoleh bahwa seluruh komponen termasuk dalam katagori Valid dengan skor rata- rata keseluruhan sebesar 3,22 dengan skor maksimal 4,00. Simpulan, bahwa bahan ajar barbasis karakter dalam bentuk buku ajar konsep dasar IPS valid.
\end{abstract}

Kata Kunci: Bahan Ajar, Karakter, IPS PGSD

\begin{abstract}
This article discusses the process in designing teaching materials in the form of Social Studies Basic Concept textbooks for PGSD STKIP PGRI Lubuklinggau students. The method used by the author in designing teaching materials is part or two initial stages of the ADDIE development model which consists of the analysis, design, deleopment, implementation, and evaluation stages. The analysis phase aims to identify the curriculum, the need for teaching materials, while the design phase is to design the textbook framework and research instruments. Based on these two stages, the concept of character education is obtained which can be integrated into learning by presenting in the Social Studies Basic Concept Book so that the learning of Social Sciences Basic Concepts is more meaningful and can be one of the character reading materials for students. The analysis results obtained that all components included in the Valid category with an overall average score of 3.22 with a maximum score of 4.00. Conclusions, that the character-based teaching materials in the form of textbooks IPS basic concepts are valid.
\end{abstract}

Keywords: Teaching Materials, Characters, IPS PGSD 


\section{PENDAHULUAN}

Pendidikan IPS sebenarnya sangat erat kaitannya dengan pendidikan karakter. Hal ini terlihat pada rumusan tujuannya, bahwa pendidikan karakter atau pendidikan nilai juga bertujuan agar peserta didik menjadi warga negara yang baik. Kosep Dasar IPS merupakan bagian dari kurikulum matakuliah wajib yang harus dikuasai oleh mahasiswa program studi Pendidikan Guru Sekolah Dasar (PGSD).

Sebagai upaya mewujudkan ketercapaian pendidikan IPS diperlukan berbagai upaya Upaya tersebut salah satunya adalah penggunaan bahan ajar. Bahan ajar itu dikatakan unik, artinya bahan ajar hanya dapat digunakan untuk audiens tertentu dalam suatu proses pembelajaran tertentu dan Spesifik artinya isi bahan ajar tersebut dirancang hanya untuk mencapai tujuan dan audiens tertentu (Sadjati:2012). Dengan memanfaatkan Bahan ajar peserta didik diarahkan untuk menjadi pembelajar yang aktif karena mereka dapat membaca atau mempelajari materi yang ada dalam bahan ajar terlebih dahulu sebelum mengikuti pembelajaran.

Namun pada kenyataan di lapangan, masih ada mahasiswa yang kurang berkarakter, dilihat selama proses observasi ditemukan banyak mahasiswa yang merokok di lingkungan kampus dan mengucapkan kata-kata kasar. Permasalahan lain yang di hadapi adalah kurang tersedianya bahan ajar. Khususnya dalam konteks Konsep Dasar IPS. Namun pada kenyataannya pada proses pembelajaran terdapat kekurangan sumber belajar. Di Lubuklinggau bahan ajar penunjang proses pembelajaran masih kurang. Terkhusus untuk bahan ajar Konsep Dasar IPS sendiri di Perpustakaan STKIP PGRI Lubuklinggau masih terbatas akan buku penunjang, hal ini disebabkan karena Program Studi PGSD baru berjalan 3 Tahun. Selain itu di perpustakaan Kota yang menjadi pusat baca di Lubuklinggau, buku yang tersedia sangat minim dan belum mencukupi kebutuhan mahasiswa dalam membantu proses pembelajaran berlangsung. Berdasarkan peneliti terdahulu yang di lakukan oleh I Made Tegeh, dengan judul Pengembangan Bahan Ajar Model Penelitian Pengembangan Dengan Model Addie.

Bahan ajar merupakan keseluruhan materi pelajaran sebagai bagian dari isi kurikulum. Dalam suatu sistem pembelajaran, bahan ajar merupakan subsistem yang turut berpengaruh terhadap pencapaian kompetensi para pebelajar di samping tujuan, metode, media, dan penilaian. (Hamalik dalam Nardi, 2017). Menurut Sanjaya,(2008) bahan ajar adalah segala sesuatu yang menjadi isi kurikulum yang harus dikuasai oleh siswa sesuai dengan kompetensi dasar dalam rangka pencapaian standar kompetensi setiap mata pelajaran dalam satuan pendidikan tertentu.

Menurut panduan pengembangan bahan ajar Depdiknas (2007) disebutkan bahwa bahan ajar berfungsi sebagai 1)Pedoman bagi guru yang akan mengarahkan semua aktivitasnya dalam proses pembelajaran, sekaligussubstansi kompetensi yang seharusnya diajarkan kepada siswa; 2)Pedoman bagi siswa yang akan mengarahkan semua aktivitasnya dalam proses pembelajaran, sekaligus substansi kompetensi yang seharusnya dipelajari/dikuasainya.

Berdasarkan uraian mengenai definisi bahan ajar, maka dapat disimpulkan bahwa bahan ajar adalah segala bentuk bahan yang disusun secara sistematis dan disesuaikan dengan kebutuhan siswa sehingga tercipta suasana yang memungkinkan siswa belajar.

IPS merupakan suatu program pendidikan dan bukan sub-disiplin ilmu tersendiri, sehingga tidak akan ditemukan baik dalam nomenklatur filsafat ilmu, disiplin ilmu-ilmu sosial 
(social science), maupun ilmu pendidikan (Sumantri. 2001). Social Scence Education Council (SSEC) dan National Council for Social Studies (NCSS), menyebut IPS sebagai "SocialScience Education" dan "Social Studies". Dengan kata lain, IPS mengikuti cara pandang yang bersifat terpadu dari sejumlah mata pelajaran seperti:geografi, ekonomi, ilmu politik, ilmu hukum, sejarah, antropologi, psikologi, sosiologi, dan sebagainya.

Sumaatmadja (2008) mengemukakan bahwa "Secara mendasar pengajaran IPS berkenaan dengan kehidupan manusia yang melibatkan segala tingkah laku dan kebutuhannya". IPS berkenaan dengan cara manusia menggunakan usaha memenuhi kebutuhan materinya, memenuhi kebutuhan budayanya, kebutuhan kejiwaannya, pemanfaatan sumber yang ada dipermukaan bumi, mengatur kesejahteraan dan pemerintahannya, dan lain sebagainya yang mengatur serta mempertahankan kehidupan masyarakat manusia.

Menurut Kementerian Pendidikan Nasional (2010) "Karakter adalah watak, tabiat, akhlak, atau kepribadian seseorang yang terbentuk dari hasil internalisasi berbagai kebajikan (virtues) yang diyakini dan digunakan sebagai landasan untuk cara pandang, berpikir, bersikap, dan bertindak". Pendidikan Karakter menurut (Albertus: 2010) adalah diberikannya tempat bagi kebebasan individu dalam mennghayati nilai-nilai yang dianggap sebagai baik, luhur, dan layak diperjuangkan sebagai pedoman bertingkah laku bagi kehidupan pribadi berhadapan dengan dirinya, sesame dan Tuhan.

Thomas Lickona mengemukakan bahwa "Memiliki pengetahuan nilai moral itu tidak cukup untuk menjadi manusia berkarakter, nilai moral harus disertai dengan adanya karakter

yang bermoral" (1992). "Termasuk dalam karakter ini adalah tiga komponen karakter (components of good character) yaitu pengetahuan tentang moral (moral knowing), perasaan tentang moral (moral feeling), dan perbuatan bermoral (moral actions). Hakikat pendidikan karakter dalam konteks pendidikan Indonesia adalah pendidikan nilai, yakni pendidikan nilainilai luhur yang bersumber dari budaya bangsa Indonesia sendiri, dalam rangka membina kepribadian generasi muda. (Gunawan: 2012)

\section{METODE PENELITIAN}

Metode penelitian yang digunakan dalam penelitian ini adalah metode Researchand Development (R\&D). Memvalidasi produk, berarti produk itu telah ada, dan peneliti hanya menguji efektivitas atau validitas produk tersebut. Mengembangkan produk dalam arti yang luas dapat berupa memperbaharui produk yang telah ada (sehingga menjadi lebih praktis, efektif, dan efisien) atau menciptakan produk baru (yang sebelumnya belum pernah ada). Artikel ini membahas tentang dua tahapan awal penelitian untuk menghasilkan produk bahan ajar berupa Buku ajar Konsep Dasar IPS berbasis Karakter Desain dan pengembangan Buku ajar menggunakan pendekatan model ADDIE (Analysis-Design-Development ImplementationEvaluation).

Langkah-langkah pengembangan LKS yang digunakan dalam penelitian ini adalah pengembangan perangkat model ADDIE yangmeliputi langkah: analysis, design, development, 
implementation, dan evaluation(Sugiyono, 2017:38). Prosedur pengembanganyang dilakukan peneliti dalam merancang buku ajar adalah: 1)Analysis, pada tahap ini dilakukan analisis masalah perlunya suatu pengembangan. Tahap analisis memuat analisis kurikulum, dan analisis kebutuhan. Pada tahap ini dilakukana nalisis kurikulumn untuk mengetahui kompetensi inti dan kompetensi dasar yang termuat dalam standar isi.Analisis kurikulum dilakukan untuk mengetahui kompetensi apa saja yang harusdisiapkan dalam bahan ajar yang akan dikembangkan sesuai dengan tuntutan kurikulum yang berlaku. Berikutnya dilakukan analisis kebutuhan analisis kebutuhan dapat dilakukan dengan menganalisis bahan ajar yang tersedia. Pada tahap ini akan diketahui bahan ajar apa yang perlu dikembangkan untuk memfasilitasi siswa dalam mempelajari materi pembelajaran; 2)Design, setelah tahap analisis selesai, tahap selanjutnya yaitu tahap design. Pada tahap ini Kegiatan yang dilakukan pada tahap design diawali dengan penyusunan rancangan bahan ajar Kegiatan ini meliputi penyusunankeseluruhan isi bahan ajar berbasis karakter yang sesuai dengan RPS matakuliah Konsep Dasar IPS. Kegiatan yang dilakukan pada tahap penyusunan rancangan ini adalah menyusun peta kebutuhan bahan ajar, menyusun kerangka bahan ajarr, mengumpulan buku referensi. Selanjutnya dalam tahap ini membuat instrumen penelitian. Instrumen disusun dengan memperhatikan aspek penilaian Kevalidan bahan ajar yaitu aspek komponen kelayakan isi,kelayakan penyajian, kelayakan bahasa, Pada kegiatan ini dilakukan membuat instrumen penelitian yang meliputi instrument penilaian oleh ahli bahasa, ahli materi, dan ahli media, serta angket respon mahasiswa; 3)Development, adalah menyusun rancangan bahan ajar konsep dasar IPS berbasis karakter dan melakukan validasi sebelum diujicobakan pada responden yaitu mahasiswa PGSD; 4)Implementation, adalah proses Mengujicobakan bahan ajar konsep dasar IPS berbasis Karakter, dengan membagikan angket respon tentang bahan ajar tersebut pada mahasiswa; 5)Evaluation, melakukan analisis dan perbaikan-perbaikan terhadap kesalahan yang terjadi selama proses pengambilan data.

\section{HASIL PENELITIAN}

Pada tahap analisis yang meliputi analisis kurikulum, dan analisis kebutuhan Pada tahap ini, peneliti akan menganalisis masalah yang melatarbelakangi pengembangan buku ajar ini. Kemudian peneliti menganalisis syarat-syarat buku ajar yang akan dibuat. Penelitin akan merancang Buku ajar dengan mengidentifikasi materi.

Berdasarkanhasil analisis kebutuhan diperoleh bahwa bahan ajar yang tersedia saat ini atau yang kerap digunakan mahasiswa adalah buku cetak yang beredar di pasaran, dalam hal sajian materi terkesan abstrak, dan masih umum tentang pembelajaran IPS belum spesifik ke arah materi Konsep dasar IPS . Maka dari itu dibutuhkan bahan ajar menggunakan konteks yang lebih spesifik dalam hal ini konteks Konsep dasar IPS berbasis karakter.

Tahap Desain adalah menentukan kerangka Buku ajar yang terdiri dari 1) Sampul Buku 2) Halaman identitas Buku, 3) Kata Pengantar, 4) Daftar Isi, 5) Pendahuluan 6) Materi , 7) Kesimpulan Akhir 8) evaluasi 9) Daftar Pustaka.

Tabel 1 


\section{Struktur Bahan Ajar}

\begin{tabular}{cl}
\hline $\begin{array}{c}\text { BAGIAN BAHAN } \\
\text { AJAR }\end{array}$ & \multicolumn{1}{c}{ ISI } \\
\hline \multirow{2}{*}{ Bagian Awal } & Halaman Sampul Depan \\
\cline { 2 - 2 } & Identitas buku \\
\cline { 2 - 2 } Bata Pengantar & Daftar Isi \\
\hline \multirow{2}{*}{ Bagian Isi } & $\begin{array}{l}\text { Pendahuluan } \\
\text { Materi }\end{array}$ \\
& Kesimpulan \\
\cline { 2 - 2 } & Evaluasi \\
\cline { 2 - 2 } Baftar Pustaka \\
\hline \multirow{2}{*}{ Bagian Akhir } & Daftar Pustaka \\
\cline { 2 - 2 } & Sampul Belakang \\
\hline
\end{tabular}

Kerangka Buku ajar tersebut akan disusun secara sistematis sehingga siswa bisa mempelajari materi yang disajikan melalui deskripsi singkat tentang materi Konsep dasar IPS, sehingga siswa mengalami pengalaman belajar dan mendapatkan pengetahuan dan tidak kesulitan dalam mendapatkan bahan belajar berupa buku.

Penyusunan Rancangan Buku ajar mengacu pada instrumen penilaian kevalidan bahan ajar yaitu aspek komponen kelayakan isi, kelayakan penyajian, dan kelayakan bahasa. Untuk mempermudah dalam proses validasi dari ahli, maka aspek-aspek tersebut dideskripsikan menjadi beberapa butir beserta deskriptornya, sehingga proses validasi lebih jelas dan terukur secara kualitatif.

Tabel 2

Validasi Ahli

\begin{tabular}{lccccc}
\hline No & Validator & $\begin{array}{c}\text { Jumlah butir } \\
\text { Pernyataan }\end{array}$ & $\begin{array}{c}\text { Skor } \\
\text { yang } \\
\text { Diperoleh }\end{array}$ & $\begin{array}{c}\text { Skor } \\
\text { rata-rata }\end{array}$ & Kategori \\
\hline $\mathbf{1}$ & Bahasa & 11 & 39 & 3,5 & Valid \\
\hline $\mathbf{2}$ & Materi & 13 & 37 & 2,8 & Valid \\
\hline $\mathbf{3}$ & Media & 12 & 40 & 3,33 & Valid \\
\hline & Total & $\mathbf{3 6}$ & $\mathbf{1 1 6}$ & $\mathbf{3 , 2 2}$ & Valid \\
\hline
\end{tabular}

Sehingga seluruh komponen termasuk dalam katagori Valid dengan skor rata- rata keseluruhan sebesar 3,22 dengan skor maksimal 4,00. Hal yang sama juga diperoleh dari hasil penelitian yang ditulis oleh (Rohmah, Hariyono \& Sudarmiatin:2017) bahwa hasil validasi oleh ahli materi menunjukkan bahwa rata-rata persentase kevalidan sebesar 92,59\% yang berarti buku ajar sangat valid. Sementara itu, hasil validasi ahli bahasa menunjukkan rata-rata persentase 
kevalidan sebesar $75 \%$ yang berarti buku ajar tersebut valid. Secara umum, jika hasil validasi dari kedua ahli tersebut dirata-rata didapatkan hasil $84,13 \%$ yang berarti sangat valid dan layak digunakan dalam pembelajaran.

\section{PEMBAHASAN}

Proses perancangan bahan ajar berbentuk Buku Ajar yang berbasis Karakter merupakan bagian dari pengembangan pembelajaran Konsep Dasar IPS hal ini selaras dengan pandangan Ilmu Pengetahuan Sosial merupakan mata pelajaran yang diberikan mulai dari pendidikan dasar, Ellis (1997) menjelaskan tujuan pembelajaran IPS adalah:

"Social studies is designed to help children explain their world. By organization he basically meant the ability to understand and classify things with respect to how they work. Adaptation refers to the process of accommodating one self to one's environment. A child who enters school has already adapted considerably to the environment through speech, dress, rules at home, and so forth but school is designed to expand such adaptation greatly through formal learning processes, social, emotional, and physical".

Pernyataan di atas menjelaskan bahwa tujuan utama Ilmu Pengetahuan Sosial adalah untuk mengembangkan potensi siswa agar mampu beradaptasi, peka terhadap masalah sosial yang terjadi di masyarakat, memiliki sikap mental positif terhadap perbaikan segala ketimpangan yang terjadi, dan terampil mengatasi setiap masalah yang terjadi sehari-hari baik yang menimpa dirinya sendiri maupun yang menimpa masyarakat. Sejalan dengan itu, Barth (1990) menjelaskan bahwa:

Proposed that one way to integrated social studies in a scope and sequence was to apply the four skill objective: (1) gaining knowledge, (2) Processing information, (3) clarifying values and (4) engaging in social participation, in every social studies classroom.

Sesuai pendapat di atas dapat disimpulkan bahwa tujuan pembelajaran IPS yaitu memperoleh pengetahuan, mahasiswa belajar tentang diri mereka sendiri dan lingkungannya, kemudian kemampuan menggunakan dan mengamalkan pengatahuan dan ide-ide melalui ketrampilan berfikir. Tujuan yang lain adalah membentuk sikap yang diperlukan untuk tingkah laku berfikir (intellectual behavior) dan tingkah laku sosial (social behavior). Tujuan-tujuan tersebut bermuara pada tujuan utama IPS yaitu untuk melatih pebelajar untuk bertanggung jawab sebagai warga Negara yang baik serta mempersiapkan generasi muda untuk menjadi seorang humanis, rasional, berpartisipasi dalam kehidupan dunia dan menjadi meningkat kesadaran untuk saling membutuhkan dalam hidupnya.

Dengan mencermati uraian tentang pengertian dan tujuan IPS, akan terlihat bahwa pendidikan IPS sebenarnya sangat erat kaitannya dengan pendidikan karakter. Hal ini terlihat pada rumusan tujuannya, bahwa pendidikan karakter atau pendidikan nilai juga bertujuan agar peserta didik menjadi warga negara yang baik. Bahkan, secara tegas Gross menyatakan, "Values Education associal studies "to prepare students to bewell-fungtioning citizens in democratic society” (Darmadi, 2007). istilah pendidikan nilai ini seringdisamakan dengan pendidikan religius,pendidikan budi pekerti, pendidikanakhlak mulia, pendidikan moral ataupendidikan 
karakter itu sendiri. Pendidikankarakter, pendidikan moral, atau pendidikan budi pekerti itu dapatdikatakan sebagai upaya untuk mempromosikandan menginternalisasikannilai-nilai utama, atau nilai-nilai positifkepada warga masyarakat agar menjadi warga bangsa yang percaya diri, tahanuji dan bermoral tinggi, demokratis dan bertanggung jawab serta survive dalamkehidupan bermasyarakat. Dengan demikian,pendidikan karakter merupakanproses pembudayaan dan pemanusiaan.

\section{SIMPULAN}

Proses Pembelajaran yang berkualitas harus didukung berbagai aspek, satu diantara aspek yang utama adalah bahan ajar, jika dalam proses pembelajaran bahan ajar yang menjadi salah satu sumber belajar kurang maka tidak akan tercipta suasana belajar yang kondusif sehingga akan menciptakan sebuah proses pembelajaran yang kurang bermakna dan pendidikan menjadi kurang berkarakter. Dalam penelitian ini telah dikembangkan sebuah produk untuk menunjang proses pembelajaran yaitu, bahan ajar yang valid, praktis dan efektif pada mata kuliah Konsep Dasar IPS yang berkarakter bagi Mahasiswa PGSD.

\section{DAFTAR PUSTAKA}

Akbar, S. (2013). Instrumen Perangkat Pembelajaran. Bandung: PT Remaja Rosdakarya

Albertus, D., K. (2010). Pendidikan Karakter Strategi Mendidik Anak di Zaman Global, Jakarta: PT.Grasindo.

Barth, J., L. (1990). Methods of instruction in social studies education. New York: University Press of America.

Benn, A., P. (2009). Model Desain Sistem Pembelajaran. Jakarta:PT. Dian Rakyat.

Depdiknas. (2006). Pedoman Memilih dan Menyusun Bahan Ajar. Jakarta: Direktorat Jenderal Pendidikan Dasar dan Menengah.

Departemen Pendidikan Nasional, (2010). Pendidikan Karakter Teori \& Aplikasi, Jakarta: Direktorat Jenderal Manajemen Pendidikan dan Menengah Kementerian Pendidikan Nasional.

Dirjen Dikti Depdiknas. (2006). Standar Kompetensi Guru Kelas SD/MI Lulusan S1 PGSD. Jakarta: Dit. Ketenagaan. Ditjen Dikti.

Ellis. A., K. (1997). Teaching and learning elementary social studies. Boston: Allyn \& bacon A Viacom Company.

Gunawan, H . (2012). Pendidikan Karakter Konsep dan Implementasi. Bandung:Alfabeta.

Hamid, D. (2007). Konsep Dasar Pendidikan Moral. Bandung: Alfabeta.

Lestari, I. (2013). Pengembangan Bahan Ajar Berbasis Kompetensi. Padang:Akademia Permata.

Lickona, T. (1992). Educating for character, how our schools can teach respect and responsibility. New York: Bantam Books

Mulyatiningsih, E. (2011). Metode Penelitian Terapan Bidang Pendidikan. Bandung: Alfa Beta

Nardi, M. (2017). Pengembangan Bahan Ajar Mata Kuliah Pembelajaran IPS SD Model 4-P Dipadukan Dengan Reciprocal Teaching https://ejournal.stkipsantupaulus.ac.id/index.php/jipd/issue/view/9

Prastowo, A. (2014). Pengembangan Bahan Ajar Tematik Tinjauan Teoritis dan Praktis. Jakarta: Kencana Prenadamedia Group. 
Rohmah, D., F. (2017). Pengembangan Buku Ajar Ips Sd Berbasis Kontekstual (http://journal.um.ac.id/index.php/jptpp/article/view/9200/4445).

Sanjaya,W.(2012). Media Komunikasi Pembelajaran. Jakarta: Kencana Prenada Media Group

Sapriya. (2006). Konsep Dasar IPS. Bandung: UPI PRESS. PT Remaja Rosdakarya.

Seels, B., R. (1994). Teknologi Pembelajaran. Jakarta : Penerbit Universitas Negeri Jakarta

Setyosari, Punaji. (2012). Metode Penelitian Pendidikan dan Pengembangan. Jakarta: Kencana Prenada Media Group.

Sugiyono. (2016). Metode Penelitian Kuantitatif Kualitatif dan R\&D. Bandung: Alfabeta.

Sumaatmadja, N.(2008). Konsep Dasar IPS. Jakarta. UT

Sumantri, N. (2001). Pembaharuan Pendidikan IPS. Bandung : Rosda Karya.

Wina, S. (2008). Perencanaan dan Desain Sistem Pembelajaran. Bandung:Prenada Media Group.

Zulfiati, H., M., \& Chairiyah. (2014). Bahan ajar pendidikan IPS SD. Yogyakarta : Universitas Sarjanawiyata Taman Siswa. 